\title{
Deficiência Física Adquirida e Aspectos Psicológicos: Uma Revisão Integrativa da Literatura
}

\author{
Acquired Physical Disability and Psychological Aspects: An Integrative Literature Review \\ Discapacidad Física Adquirida y Aspectos Psicológicos: Una Revisión Bibliográfica \\ Integradora
}

\author{
Talitha Kshesek Pizarro de Oliveira ${ }^{1}$ \\ Camila Maia de Oliveira Borges Paraná \\ Pontifícia Universidade Católica do Paraná (PUC-PR)
}

\begin{abstract}
Resumo
Objetivando investigar os aspectos psicológicos relacionados à deficiência física adquirida na fase adulta, o estudo utilizou como método a revisão de literatura integrativa, com abordagem qualitativa de artigos nacionais publicados no período entre 2009 e 2018, mediante buscas efetuadas nas bases CAPES, SciELO e Google Acadêmico, com os descritores "deficiência física" e "deficiência adquirida". Ao total, 10 artigos foram analisados, e os resultados sugerem que um adulto adquirir uma deficiência física pode impactar diretamente na autonomia e na autoestima, colidindo com diversos aspectos psicológicos ligados à sexualidade, a relações familiares, sociais, afetivas e profissionais. A análise dos estudos permite concluir que os aspectos psicológicos se inter-relacionam e que a reestruturação destes pode promover uma melhor qualidade de vida. Destaca-se a necessidade de publicações que tratem dessas questões, visando a uma compreensão mais aprofundada acerca do impacto das deficiências físicas adquiridas.

Palavras-chave: autoestima, autonomia, inclusão, Psicologia, qualidade de vida
\end{abstract}

\begin{abstract}
Aiming to investigate the psychological aspects related to a physical disability acquired in adulthood, the study used the method of integrative literature review, with a qualitative approach of national articles published in the period between 2009 and 2018, through searches carried out in the CAPES, SciELO, and Google Scholar database, with the descriptors "physical disability" and "acquired disability". In total, 10 articles were analyzed and the results suggest that an adult acquiring a physical disability can directly impact autonomy and self-esteem, clashing with various psychological aspects related to sexuality, family, social, affective, and professional relationships. The analysis of the studies concludes that the psychological aspects are interrelated and that their restructuring can promote a better quality of life. The study highlighted the need for publications dealing with these issues, aimed at a deeper understanding of the impact of acquired physical disabilities.
\end{abstract}

Keywords: self-esteem, autonomy, inclusion, Psychology, quality of life

\section{Resumen}

Con el objetivo de investigar los aspectos psicológicos relacionados con la discapacidad física adquirida en la edad adulta, el estudio utilizó el método de revisión de literatura integradora, con enfoque cualitativo de artículos nacionales publicados en el período comprendido entre 2009 y 2018, por medio de búsquedas realizadas en las bases de datos CAPES, SciELO y Google Académico, con los descriptores "discapacidad física" y "discapacidad adquirida". En total, se analizaron 10 artículos y los resultados sugieren que un adulto que adquiere una discapacidad física puede tener directamente afectadas la autonomía y la autoestima, chocando con varios aspectos psicológicos relacionados con la sexualidad, la familia, las relaciones sociales, afectivas y profesionales. El análisis de los estudios nos permite concluir que todos los aspectos psicológicos están interrelacionados y que su reestructuración puede promover una mejor calidad de vida. Se destaca la necesidad de publicaciones que aborden estos temas, con el objetivo de una comprensión más profunda del impacto de las discapacidades físicas adquiridas.

Palabras clave: autoestima, autonomía, inclusión, Psicología, calidad de vida

\footnotetext{
${ }^{1}$ Endereço de contato: Guilherme Marconcin, 77, Curitiba, PR. CEP: 81570-410. Telefone: (41) 99564-0966. E-mail: talithakshesek@gmail.com
} 


\section{Introdução}

Segundo dados de uma pesquisa realizada pela Organização Mundial da Saúde (OMS, 2011), estima-se que cerca de 15\% da população mundial tenha alguma deficiência. Em nível da população brasileira, a partir de dados do censo demográfico realizado em 2010 pelo Instituto Brasileiro de Geografia e Estatística (IBGE, 2013), 23,9\% dessa população declara ter alguma deficiência, seja ela física, seja ela visual, auditiva ou intelectual.

Ao longo da história da humanidade, verifica-se que as pessoas com deficiência foram estigmatizadas, segregadas e rejeitadas no meio social. O estudo dos autores Pimentel S e Pimentel M. (2018) fornece dados históricos, por meio dos quais constata-se que em cada época houve uma maneira diferente de tratar o indivíduo com deficiência; em algumas, eles eram rejeitados pela família ainda quando crianças e condenados à morte; e, em outras, eram tratados com caridade ou considerados como um castigo para demonstração da ira divina. Os mesmos autores reiteram ainda que a deficiência era considerada como uma anomalia e estava em uma posição de inferioridade.

O Decreto 3298/99 divide a deficiência em cinco categorias: física, auditiva, visual, intelectual e múltipla, apontando as características que a pessoa deve ter para se enquadrar em alguma delas (Brasil, 1999). No estatuto da pessoa com deficiência, consta que a deficiência física pode ser vista como qualquer alteração que prejudique o desempenho esperado de uma parte do corpo (Brasil, 2015).

Segundo a Pesquisa Nacional de Saúde realizada pelo IBGE em 2013, 1,3\% da população brasileira declarou ter deficiência física, sendo 0,3\% de origem congênita e 1,0\% adquirida em decorrência de doença ou acidente (IBGE, 2013). As deficiências congênitas são aquelas em que o indivíduo já nasce com essa condição, podendo ser decorrentes do parto ou de doenças que o bebê apresenta, enquanto as deficiências físicas adquiridas são as que o indivíduo passa a ter durante a vida, após o nascimento, e geralmente ocorrem por sequelas de doenças vasculares, diabetes ou traumas, como no caso de acidentes de trânsito, ferimentos por armas de fogo ou acidentes de trabalho com máquinas (Mattos, 2015).

Em vista disso, a revisão de literatura proposta neste trabalho buscou compreender quais são os aspectos psicológicos relacionados à nova condição de vida de uma pessoa acometida pela deficiência física adquirida na fase adulta.

\section{Método}

Trata-se de um estudo teórico de caráter exploratório, no qual se utilizou como método a revisão integrativa. A revisão integrativa de literatura é um método criterioso que reúne de maneira ampla diversos estudos sobre um determinado problema de pesquisa, combinando pesquisas teóricas e práticas, a fim de sistematizar as informações sobre um tema (Souza; Silva, \& Carvalho, 2010). Assim, este método pode apresentar como resultado um quadro que reunirá informações relativas aos aspectos psicológicos após uma deficiência física adquirida na fase adulta.

A seleção dos estudos foi realizada a partir dos objetivos de pesquisa, a saber: 1) investigar os aspectos psicológicos relacionados à deficiência física adquirida na fase adulta; 2) compreender o impacto da deficiência física adquirida na vida de uma pessoa em relação aos processos subjetivos; 3 ) investigar como as relações familiares, sociais e afetivas podem 
contribuir para a reestruturação da autoestima do indivíduo; e 4) identificar se a autonomia na realização de atividades cotidianas interfere positivamente na autoestima.

Foram selecionadas publicações no período entre 2009 e 2018, com o objetivo de priorizar as mais recentes e estudar com maior aprofundamento cada uma. Os artigos foram escolhidos pelo título, resumo e proximidade ao tema e aos objetivos de pesquisa. A busca foi feita nas seguintes bases de dados: Portal de Periódicos do Google Acadêmico (via Coordenação de Aperfeiçoamento de Pessoal de Nível Superior [CAPES]); Portal da CAPES e Scientific Eletronic Library Online (SciELO). Como descritores, foram utilizados os seguintes termos: "deficiência física" AND "deficiência adquirida". Como critério de inclusão, selecionaram-se artigos publicados no idioma português, e não houve seleção quanto ao tipo de estudo (revisão sistemática, estudo de caso etc.).

\section{Resultados}

A partir da busca nas três bases de dados selecionadas para esta pesquisa, foram encontrados 426 artigos. A Tabela 1 apresenta a distribuição desses artigos de acordo com cada base.

Tabela 1

Distribuição dos artigos a partir das bases de dados selecionadas

\begin{tabular}{lcccc}
\hline \multicolumn{1}{c}{ Base } & $\begin{array}{c}\text { Total } \\
\text { de artigos }\end{array}$ & $\begin{array}{c}\text { Artigos } \\
\text { duplicados }\end{array}$ & $\begin{array}{c}\text { Artigos } \\
\text { selecionados }\end{array}$ & $\begin{array}{c}\text { Artigos } \\
\text { recuperados }\end{array}$ \\
\hline Google Acadêmico & 338 & 13 & 8 & 8 \\
\hline CAPES & 76 & 7 & 8 & 2 \\
\hline SciElo & 12 & 3 & 7 & 2 \\
\hline Total & 426 & 403 & 23 & 10 \\
\hline
\end{tabular}

Observou-se a repetição de alguns artigos nas bases pesquisadas. Após a eliminação dos repetidos, restaram 403 estudos. Posteriormente, as publicações foram selecionadas para análise a partir do título, resumo e relação com o objetivo da pesquisa. Foram descartados 380 artigos que não estavam relacionados com o tema pesquisado, restando 23 artigos. Após a análise e leitura dos resumos e dos textos desses 23 artigos, verificou-se que 13 tratavam de deficiência física congênita ou abarcavam outros tipos de deficiência (visual, auditiva, múltiplas), ou que então tratavam de deficiência física adquirida em outras fases da vida.

Portanto, ao final da busca, 10 artigos foram selecionados, pois tratavam especificamente de deficiência física adquirida na fase adulta e tinham relação com os objetivos desta pesquisa. Em relação ao ano de publicação, verificou-se que os artigos selecionados se concentraram nos anos de 2010, com 3 (30\%) publicações, e 2015, com 3 (30\%) também, seguidos por 2018, com 2 (20\%) publicações, e pelos anos de 2014, com 1 (10\%) publicação, e 2011, igualmente com 1 (10\%). 
Tabela 2

Relação das publicações que compuseram a amostra, de acordo com base de dados, título, autor(es), ano de publicação e objetivos dos estudos

\begin{tabular}{|c|c|c|c|}
\hline Base de dados & N. & Autores, ano de publicação e título & Objetivos \\
\hline \multirow{7}{*}{$\begin{array}{l}\text { Google } \\
\text { Acadêmico }\end{array}$} & 1 & $\begin{array}{l}\text { Lima, Torres e Filho (2014) - } \\
\text { Aspectos psicológicos associados à } \\
\text { sexualidade do lesado medular }\end{array}$ & $\begin{array}{l}\text { Analisar os aspectos psicológicos } \\
\text { referentes à sexualidade de homens } \\
\text { lesados medulares }\end{array}$ \\
\hline & 2 & $\begin{array}{l}\text { Silva, Dias, Santos, Kian e Rodrigues } \\
\text { (2015) - A expressão da sexualidade } \\
\text { em homens com deficiência física } \\
\text { adquirida }\end{array}$ & $\begin{array}{l}\text { Investigar as principais mudanças que } \\
\text { a deficiência física adquirida trouxe } \\
\text { para o exercício da sexualidade }\end{array}$ \\
\hline & 3 & $\begin{array}{l}\text { Maia (2010) - A importância das } \\
\text { relações familiares para a sexualidade } \\
\text { e a autoestima de pessoas com } \\
\text { deficiência física }\end{array}$ & $\begin{array}{l}\text { Identificar o impacto da deficiência } \\
\text { adquirida e a importância das } \\
\text { relações familiares e afetivas para } \\
\text { a reestruturação emocional e da } \\
\text { autoestima }\end{array}$ \\
\hline & 4 & $\begin{array}{l}\text { Lopes, Leite (2015) - Deficiência } \\
\text { adquirida no trabalho em policiais } \\
\text { militares: significados e sentidos }\end{array}$ & $\begin{array}{l}\text { Identificar o conjunto de significações } \\
\text { relacionado à deficiência para } \\
\text { policiais com deficiência adquirida }\end{array}$ \\
\hline & 5 & $\begin{array}{l}\text { Santos, Dias, Kian, Silva, Rodrigues } \\
\text { (2015) - Homens com deficiência } \\
\text { física adquirida: estigmas e } \\
\text { preconceitos vivenciados que } \\
\text { interferem em sua sexualidade }\end{array}$ & $\begin{array}{l}\text { Investigar o impacto dos estigmas } \\
\text { e preconceitos que interferem na } \\
\text { sexualidade masculina de indivíduos } \\
\text { com deficiência física adquirida }\end{array}$ \\
\hline & 6 & $\begin{array}{l}\text { Rodrigues, Antunes (2010) - } \\
\text { Considerações sobre o paciente com } \\
\text { lesão raquimedular ou vítima de } \\
\text { trauma: um estudo qualitativo }\end{array}$ & $\begin{array}{l}\text { Identificar as condições físicas } \\
\text { e emocionais apresentadas por } \\
\text { pacientes vítimas de traumas } \\
\text { automobilísticos }\end{array}$ \\
\hline & 7 & $\begin{array}{l}\text { Carvalho-Freitas, Silva, Tette, Veloso } \\
\text { Rocha (2018) - Retorno às atividades } \\
\text { laborais entre amputados: qualidade } \\
\text { de vida no trabalho, depressão e } \\
\text { ansiedade }\end{array}$ & $\begin{array}{l}\text { Investigar entre pessoas amputadas } \\
\text { possíveis relações entre a percepção } \\
\text { de satisfação com as condições de } \\
\text { trabalho, os sintomas de depressão e } \\
\text { de ansiedade e suas associações com } \\
\text { o desejo de retornar ao trabalho }\end{array}$ \\
\hline CAPES & 8 & $\begin{array}{l}\text { Resende, Gouveia (2011) - Qualidade } \\
\text { de vida em adultos com deficiência } \\
\text { física }\end{array}$ & $\begin{array}{l}\text { Investigar a qualidade de vida nos } \\
\text { domínios: bem-estar subjetivo, } \\
\text { competências comportamentais, } \\
\text { qualidade de vida e condições } \\
\text { ambientais }\end{array}$ \\
\hline \multirow[b]{2}{*}{ SciELO } & 9 & $\begin{array}{l}\text { Santos, Carvalho-Freitas (2018) - } \\
\text { Sentidos do trabalho para pessoas } \\
\text { com deficiência adquirida }\end{array}$ & $\begin{array}{l}\text { Compreender os sentidos do trabalho } \\
\text { para pessoas com deficiência } \\
\text { adquirida }\end{array}$ \\
\hline & 10 & $\begin{array}{l}\text { Martins, Barsaglini (2010) - Aspectos } \\
\text { da identidade na experiência } \\
\text { da deficiência física: um olhar } \\
\text { socioantropológico }\end{array}$ & $\begin{array}{l}\text { Analisar a experiência da deficiência } \\
\text { física enfocando a identidade das } \\
\text { pessoas sobre o "ser e sentir-se } \\
\text { deficiente" }\end{array}$ \\
\hline
\end{tabular}


Com a leitura dos artigos selecionados, foi possível identificar os aspectos psicológicos relacionados à nova condição de vida de pessoas acometidas pela deficiência física na fase adulta (Maia, 2010; Martins, \& Barsaglini, 2010; Rodrigues, \& Antunes, 2010; Resende, \& Gouveia, 2011; Lima, Torres, \& Rachid, 2014; Lopes, \& Leite, 2015; Santos, Dias, Kian. Silva, \& Rodrigues, 2015; Silva, Santos, Kian, \& Rodrigues, 2015; Carvalho-Freitas, Silva, Tette, Veloso, \& Rocha, 2018; Santos, \& Carvalho-Freitas, 2018). Foram encontrados autores em comum nos textos da amostra, a saber: os autores Santos, Dias, Kian, Silva e Rodrigues escreveram os artigos de n. 2 e 5, e a autora Carvalho-Freitas escreveu os artigos de n. 7 e 9.

Quanto ao teor dos artigos estudados, foram identificados diversos aspectos psicológicos envolvidos no processo de aquisição de uma deficiência física, que seguem descritos na Tabela 3.

Tabela 3

Descrição dos principais aspectos encontrados nos artigos da amostra

\begin{tabular}{ll}
\hline $\mathbf{N}$. & Aspectos abordados \\
\hline $\mathbf{1}$ & Autoestima, autonomia e processos subjetivos; sexualidade \\
\hline $\mathbf{2}$ & Sexualidade \\
\hline $\mathbf{3}$ & $\begin{array}{l}\text { Autoestima, autonomia e processos subjetivos; sexualidade; relações sociais, fa- } \\
\text { miliares e afetivas }\end{array}$ \\
\hline $\mathbf{4}$ & Relações sociais, familiares e afetivas; profissão \\
$\mathbf{5}$ & $\begin{array}{l}\text { Autoestima, autonomia e processos subjetivos; sexualidade; relações sociais fa- } \\
\text { miliares e afetivas }\end{array}$ \\
\hline $\mathbf{6}$ & $\begin{array}{l}\text { Autoestima, autonomia e processos subjetivos; relações sociais, familiares e } \\
\text { afetivas }\end{array}$ \\
\hline $\mathbf{7}$ & Autoestima, autonomia e processos subjetivos; profissão \\
$\mathbf{8}$ & Autoestima, autonomia e processos subjetivos; relações sociais, familiares e \\
\hline $\mathbf{9}$ & afetivas \\
\hline $\mathbf{1 0}$ & Profissão \\
\hline
\end{tabular}

Para uma melhor visualização dos temas abordados nos estudos da amostra e os aspectos psicológicos relacionados, foi elaborado um Diagrama de Venn (Figura 1), cujos números representam os artigos já citados anteriormente. 


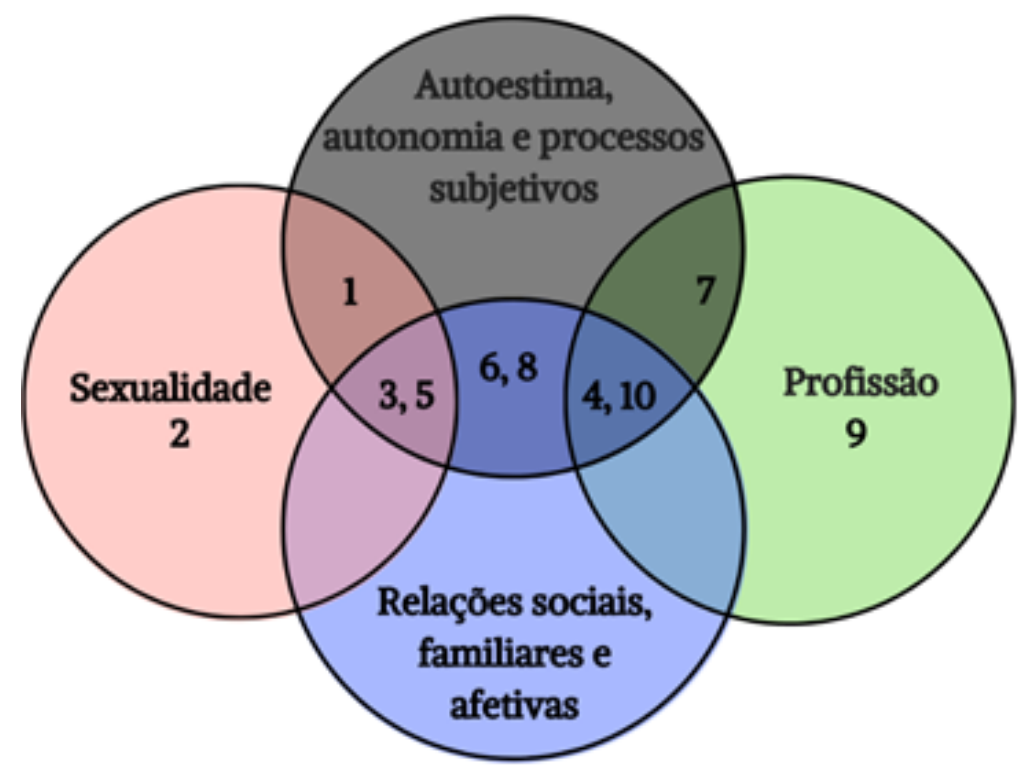

Figura 1. Diagrama de Venn: temas abordados pelos estudos da amostra. Fonte: Dados da pesquisa.

O diagrama de Venn (Figura 1) evidencia que a maioria dos temas se inter-relacionam, e que o foco em apenas um aspecto específico apareceu somente em dois artigos (2 e 9). Enquanto quatro estudos relacionaram três temas principais $(3,4,5$ e 10), outros quatro focaram apenas em dois temas (1, 6, 7 e 8).

\section{Discussão dos Resultados}

Para uma melhor compreensão dos aspectos psicológicos relacionados à deficiência física adquirida, reuniram-se os resultados dos artigos incluídos na presente revisão integrativa em quatro categorias temáticas, a saber: 1) autoestima, autonomia e processos subjetivos; 2) sexualidade; 3) relações sociais e familiares; e 4) profissão. Essas categorias serão discutidas individualmente, a fim de se verificar o impacto da experiência da deficiência física na fase adulta.

\section{Autoestima, Autonomia e Processos Subjetivos}

A autoestima enquadra a maneira como cada indivíduo aceita a si mesmo, seus pensamentos e sentimentos sobre sua imagem corporal, seus aspectos emocionais e sociais, enquanto a autonomia corresponde à realização de atividades (Maia, 2010). Os processos subjetivos são os principais aspectos identificados por sofrerem impacto da deficiência física adquirida, como: a identidade, a autoimagem, o humor, a autoestima e a motivação. Verificou-se que a autoestima, a autonomia e demais aspectos psicológicos vivenciados foram abordados por sete artigos (70\%), mas é importante salientar que é uma categoria vinculada às demais.

A aquisição da deficiência física na fase adulta gera um momento de diminuição da autoestima, visto que, inicialmente, existe uma negação da mudança na aparência do corpo (Maia, 2010). A nova condição propicia sensações de impotência que são reforçadas pela falta da completa autonomia que existia anteriormente à circunstância. O estudo de Maia (2010) ressaltou que existem estereótipos e papéis sociais atribuídos aos homens e mulheres, e, no 
momento em que os indivíduos não seguem esses padrões, acabam sendo discriminados. Por isso, adultos acometidos por uma deficiência física podem sentir-se inadequados e inferiores, criando uma autoimagem negativa (Lima, et al 2014; Maia, 2010; Santos et al., 2015).

As mudanças na autoimagem contribuem para a redução da autoestima, podendo levar os sujeitos a apresentar sentimentos de incompletude e de incapacidade, assim como a ter preocupações sobre a exposição em público (Carvalho-Freitas et al., 2018). A autora Maia (2010) complementou ressaltando que, no caso de mulheres, a questão da autoestima se torna ainda mais complicada, pois já existe um padrão imposto culturalmente quanto ao "corpo perfeito" em que pessoas do gênero feminino são intensamente cobradas. Dessa maneira, mulheres que adquirem uma deficiência física na fase adulta demonstram se preocupar mais com a atratividade pessoal, enquanto os homens que passam por isso demonstram maior preocupação com questões relacionadas à atitude e ao desempenho.

É importante ressaltar que os estudos selecionados colocaram a autoestima como inerente às respostas positivas de pares, atribuindo importância às relações sociais, familiares e afetivas. Portanto uma sociedade pautada na inclusão pode auxiliar estes sujeitos no desenvolvimento de autonomia (Maia, 2010; Martins, \& Barsaglini, 2010; Resende, \& Gouveia, 2011; Rodrigues, \& Antunes, 2010; Santos et al., 2015).

Os estudos apresentaram que alguns dos aspectos psicológicos percebidos em adultos acometidos por uma deficiência física são: dificuldade de aceitação; sentimento de culpa; vergonha por não conseguir realizar o autocuidado ou por não conseguir realizar o controle das necessidades fisiológicas; sintomas depressivos e de ansiedade; constrangimento sobre a nova aparência física; sentir-se dependente do auxílio de outras pessoas; falta de autonomia (Carvalho-Freitas et al., 2018; Rodrigues \& Antunes, 2010).

A deficiência física pode fazer com que o sujeito necessite do auxílio de outras pessoas para realizar algumas atividades, isso pode interferir no bem-estar subjetivo e pode aumentar a exigência sobre os familiares e amigos, a fim de tentar realizá-las com a maior autonomia possível. Os estudos de Martins e Barsaglini (2011), Resende e Gouveia (2011) investigaram que se reconhecer como deficiente está relacionado à interpretação subjetiva dos indivíduos sobre a própria condição. Alguns dos fatores associados a esse reconhecimento é o grau de limitação colocado pela deficiência ao desempenhar papéis sociais e atividades no dia a dia. Dessa maneira, o desenvolvimento da autonomia no que for possível pode contribuir positivamente para a reestruturação da autoestima do sujeito.

\section{Sexualidade}

A categoria sexualidade enquadra a maneira como cada indivíduo consegue vivenciá-la após a deficiência, e foi abordada por quatro estudos (40\%). Os artigos de Lima et al. (2014), Maia (2010); Silva et al. (2015) e Santos et al. (2015) apresentaram que as distorções na autoimagem, o rebaixamento da autoestima e a dificuldade de aceitação impactam diretamente na sexualidade do indivíduo. Existem deficiências físicas adquiridas que podem comprometer a ejaculação e a fertilidade, e isso pode interferir na autoestima, gerando questões emocionais que dificultam a intimidade em um relacionamento. O impacto direto que a deficiência tem na autoestima e na autoimagem transforma a relação do sujeito com a sua sexualidade. Neste processo, verifica-se que a falta de autoestima influencia uma negação 
da sexualidade, considerando que pode levar a pessoa a sentir-se incapaz de exercê-la. A falta de uma estrutura emocional segura, isto é, a falta de autoestima em razão da sensação de perda da beleza e da autonomia, pode fazer com que o sujeito passe a negar a sexualidade e, com isso, acabar negando parte de sua identidade (Lima, 2014).

O desejo sexual advém de processos mentais, portanto, mesmo após uma deficiência física adquirida, ele tende a se manter (Lima, 2014). Entretanto o indivíduo, muitas vezes, em sua relação afetiva, passa a desconsiderar esse desejo, focando apenas o aspecto físico comprometido (Lima, 2014). Adultos acometidos por uma deficiência física podem buscar adaptações para encontrar novas maneiras de sentir prazer e vivenciar a sexualidade, e o processo de reabilitação é fundamental para isso e, também, para a recuperação da autoestima e da autoimagem (Lima, 2014).

Os autores Lima (2014) e Silva et al. (2015) destacaram que, com as adaptações, o indivíduo pode identificar novas maneiras de sentir prazer, visto que alguns deficientes físicos perdem a sensibilidade dos órgãos genitais. Algumas pessoas podem apresentar perda do interesse em exercer a sexualidade por conta dessa falta de sensibilidade, enquanto outras podem identificar melhorias na vida sexual após encontrar estratégias para exercê-la. Os estudos apresentam a importância do processo de reabilitação para reduzir os danos psicológicos e buscar adaptações para a vivência da sexualidade.

A autora Maia (2010) ressaltou que a manifestação da sexualidade se torna mais complicada após a aquisição da deficiência física, e que com ela podem surgir sentimentos de solidão e inadequação. O estudo de Santos et al. (2015) complementa sustentando que os preconceitos e estigmas sobre a deficiência podem impactar na vida sexual nas relações sociais e na autoestima da pessoa deficiente. A vivência da sexualidade por esses indivíduos é vista como anormal, e uma forma de manifestação sutil desses estigmas pode ser percebida nos sentimentos de piedade e compaixão, pois são interpretados pelos deficientes como se eles fossem incapazes. Verificou-se, a partir dos relatos dos deficientes físicos participantes desse estudo, que existe sofrimento subjetivo ligado às constantes indagações acerca de como a sexualidade é vivenciada por um deficiente, como é o desejo e se possuem satisfação sexual.

Os autores Lima (2014), Maia (2010), Silva et al. (2015) e Santos et al. (2015) atestam a importância de que o indivíduo não se prive de ter relacionamentos afetivos e sexuais para a reestruturação da autoestima e salientam que as relações familiares e sociais podem contribuir também nesse âmbito, auxiliando-o a se reconhecer como uma pessoa digna de felicidade.

\section{Relações Sociais, Familiares e Afetivas}

A categoria relações sociais, familiares e afetivas compreende a relevância dos relacionamentos para uma pessoa que adquiriu a deficiência física na fase adulta, tendo sido abordada em seis artigos (Maia, 2010; Martins, \& Barsaglini, 2011; Rodrigues, \& Antunes, 2010; Resende, \& Gouveia, 2011; Lopes, \& Leite, 2015; Santos et al., 2015). Os artigos apresentam a importância da autoestima e da autoimagem para o estabelecimento de vínculos sociais e afetivos. Para adultos, a deficiência física pode restringir as interações sociais, e isso contribui para o desenvolvimento de uma fragilidade emocional; portanto as relações familiares 
podem contribuir para a reestruturação da autoestima (Resende \& Gouveia, 2011; Lopes \& Leite, 2015).

Após a aquisição da deficiência, existe prejuízo social, pois o sujeito tem suas potencialidades modificadas em diversas áreas, de maneira abrupta (Rodrigues \& Antunes, 2010; Lopes \& Leite, 2015). Os autores Lopes e Leite (2015), Resende e Gouveia (2011), Rodrigues e Antunes (2010) apontam que as relações familiares e sociais funcionam como um suporte social para que o indivíduo possa reconhecer que é amado e que pertence a um grupo. Os seis estudos selecionados (Maia, 2010; Martins \& Barsaglini, 2011; Rodrigues \& Antunes, 2010; Resende \& Gouveia, 2011; Lopes \& Leite, 2015; Santos et al., 2015) demonstraram que o suporte social é indispensável para o bem-estar subjetivo e para a qualidade de vida, pois estes são promovidos por um ambiente em que haja apoio emocional, estratégias de enfrentamento e capacidade de adaptação.

O preconceito e os estigmas sobre a deficiência física se tornam um obstáculo para a aceitação social, impactando negativamente na criação e na manutenção de vínculos de pessoas deficientes (Martins \& Barsaglini, 2010; Santos et al., 2015). Os autores Martins e Barsaglini (2010) e Santos et al. (2015) ressaltam que, além disso, o preconceito gera sofrimento psicológico e, com isso, estar e permanecer em público converte-se em um preocupante desafio para o indivíduo, visto que a exposição gera vergonha e, por isso, as pessoas tentam esconder a deficiência, a fim de evitarem ser estigmatizadas. Os estudos mostraram que o preconceito muitas vezes aparece de maneira velada em sentimentos de piedade e compaixão pelo deficiente, atribuindo-o à ideia de incapacidade e invalidez.

Os autores Martins e Barsaglini (2010) e Santos et al. (2015) complementam que pessoas direcionam à parte física alterada um olhar de pena e que os próprios indivíduos, anteriormente à condição adquirida, ao verem algum deficiente, designavam esse mesmo olhar e, hoje, percebem o quanto ele incomoda. Isso reforça que a experiência da própria deficiência faz com que a pessoa ressignifique os valores e a maneira como lida com diferenças corporais. Socialmente, a deficiência é vista como uma limitação que torna o indivíduo triste, lento, com dificuldade de autocuidado, e por isso necessita de ajuda e da piedade de outras pessoas. Essa é uma ideia generalista, visto que é colocada como se todas as pessoas com deficiência possuíssem os mesmos pensamentos e tivessem as mesmas necessidades (Martins \& Barsaglini, 2010).

Os autores Martins e Barsaglini (2010) complementam que corresponder às expectativas do grupo no desempenho de atividades está também relacionado à noção de reconhecer-se como deficiente, pois, na busca pela inclusão social, as pessoas se esforçam para realizá-las na tentativa de compensar a "falta" expressa pela limitação física.

Os autores Rodrigues e Antunes (2010) e Santos et al. (2015) apresentam a importância da família nesse contexto, visto que o processo de reabilitação é destinado também aos membros familiares, na questão dos cuidados e do auxílio no desenvolvimento da autonomia e para fomentar mudanças que devem ocorrer no âmbito familiar, a fim de que a adaptação seja bem-sucedida. Os estudos salientam que as relações familiares podem ser benéficas para o indivíduo, entretanto podem também ser desfavoráveis no sentido de que a superproteção pode acabar interferindo na reintegração social.

Martins e Barsaglini (2010) trazem informações complementares sobre as tecnologias as- 
sistivas, como próteses, cadeira de rodas e adaptadores, e em como esses acessórios podem também gerar estigma socialmente. O estudo constatou que muitos indivíduos não fazem o uso frequente desses itens por inúmeros motivos, como pela dificuldade de se adaptar, vergonha de utilizar em público e, muitas vezes, pela decepção com relação ao uso do aparelho. Por isso, o sucesso de tecnologias assistivas não está relacionado apenas à função de cumprir a demanda estabelecida, mas sim à adesão do indivíduo.

\section{Profissão}

A categoria profissão corresponde a manter-se ocupado e sentir-se útil, bem como envolve o prazer e a satisfação relacionados ao trabalho, tendo sido abordada por quatro artigos (40\%). A profissão não se aplica somente ao contexto do trabalho, pois envolve também uma identificação pessoal, e a atividade passa a englobar quem a pessoa é. O estudo de Lopes e Leite (2015) coloca que a aquisição da deficiência pode transformar a história de vida dos sujeitos acometidos por ela, pois modifica a condição de existência e, embora ela tenha uma significação negativa no início, existem fatores que podem impactar positivamente na superação, como as relações sociais.

Os autores Lopes e Leite (2015) e Rodrigues e Antunes (2010) apontam que, geralmente, quando as pessoas que adquirem uma deficiência buscam o retorno ao mercado de trabalho, esse reemprego ocorre em instituições terceirizadas, onde a atividade ocupacional é semelhante, mas a remuneração financeira é inferior, ou ocorre de maneira informal. As perdas de atividades na carreira após a deficiência podem impactar em aspectos psicológicos, pois interrompem e inviabilizam sonhos profissionais (Lopes \& Leite, 2015; Rodrigues \& Antunes, 2010).

Os autores Carvalho-Freitas et al. (2018) analisaram que deficientes que possuem restrições financeiras normalmente têm ainda menos oportunidades de ingressar no mercado de trabalho. Isso pode acontecer por conta das limitações físicas da deficiência e, também, muitas vezes, por apresentarem baixa qualificação profissional e, consequentemente, receberem poucas ofertas de trabalho. Foi verificado que os deficientes são colocados geralmente em funções operacionais e que isso acaba restringindo ainda mais a situação de retorno ao trabalho.

Ter uma profissão pode auxiliar o indivíduo com deficiência a sentir-se digno, assim como pode promover bem-estar e, por conseguinte, uma melhor qualidade de vida. Os estudos de Carvalho-Freitas et al. (2018) e Santos e Carvalho-Freitas (2018) reiteram que, na adaptação à nova condição, alguns indivíduos não possuem vontade de retornar a trabalhar e sentem-se incapazes para isso, diante das limitações físicas.

Os autores Carvalho-Freitas et al. (2018) e Santos e Carvalho-Freitas (2018) categorizam importantes aspectos que possuir um emprego possibilita, tais como: sensação de ocupação e utilidade, distração, existência de um suporte social, independência financeira, prazer e satisfação, preenchimento da vida e valorização pessoal. O trabalho evita que a pessoa se sinta ociosa, faz com que tenha uma rotina programada de atividades, tenha uma remuneração financeira e possa se sentir motivada. Foi verificado ainda que o emprego auxilia no desenvolvimento de autonomia e pode impactar na autoestima. Em muitos casos, possuir um trabalho não está relacionado à necessidade de se sentir ativo, mas sim à tentativa de 
promover melhores condições de vida para si e para os familiares.

A função exercida pode gerar alegria quando o trabalho é visto como um local de realização pessoal e de identificação dos próprios interesses e valores, podendo ainda atribuir um sentido à vida da pessoa. Ter um emprego pode elevar autoestima e a autoconfiança das pessoas, pois consolida a identidade pessoal e amplifica o senso de valor. A inclusão no mercado de trabalho pode auxiliar a reduzir o estigma social vivenciado (Carvalho-Freitas, 2018; Santos \& Carvalho-Freitas, 2018).

Foi analisado por Santos e Carvalho-Freitas (2018) que, com relação aos sentidos do trabalho, sentir-se útil e colaborando com algo/alguém foi mais recorrente no relato de indivíduos com ensino superior completo participantes de seu estudo, enquanto, nos relatos das pessoas com ensino fundamental e médio, prevaleceu o trabalho como uma maneira de distração, ocupação e realização de tarefas.

Adquirir uma deficiência física faz com que os indivíduos sejam afastados do trabalho por um período de tempo, e isso gera um importante sentimento de perda. Existem preocupações sobre o retorno relativas à reação dos demais colaboradores da empresa, dificuldade de adaptação e redução da produtividade dos indivíduos. A deficiência não deve ser vista como um impedimento para a realização das atividades laborais, e estas devem ser avaliadas e adequadas de acordo com cada necessidade (Carvalho- Freitas, 2018). Ter uma profissão, nesse contexto, pode ser visto como uma oportunidade de recomeçar e de dar novos significados às vivências.

O trabalho faz parte do projeto de vida das pessoas e, em alguns casos de deficiência física adquirida, mantém-se a mesma essência após a aquisição, e, em outros, pelo impacto desta, a relação com a profissão pode ser alterada. O desempenho de funções laborais também está ligado ao reconhecimento como deficiente. Alguns indivíduos são reconhecidos juridicamente como deficientes, por exemplo, quando recebem o benefício da aposentadoria, mas não se sentem como tal; aqui se verifica a experiência dessa condição em que a pessoa traduz as vivências e, de maneira subjetiva, identifica-se como deficiente ou não (Martins \& Barsaglini, 2011; Santos \& Carvalho-Freitas, 2018).

\section{Conclusão}

A experiência da deficiência física vivenciada na fase adulta possui impacto em diversos aspectos psicológicos do sujeito, como na autoestima, na autoimagem, na identidade, na motivação, no humor e nos demais processos subjetivos. Verificou-se que cada sujeito é dotado de uma subjetividade única e que todas as categorias estabelecidas neste estudo, para uma maior compreensão desses aspectos, inter-relacionam-se. O desenvolvimento da autonomia pode impactar positivamente na autoestima, relações familiares, sociais e afetivas, pois pode fazer com que o indivíduo sinta que pertence a um grupo e que é amado, entretanto é importante ressaltar que a família também precisa se adaptar após a deficiência, e é necessário que existam mudanças no âmbito familiar, a fim de buscar um melhor desenvolvimento dessa autonomia.

A sexualidade faz parte da identidade do ser humano, e vivenciá-la possui relação com as ideias subjetivas de cada indivíduo sobre esse tema. A deficiência e a sexualidade são dois temas que individualmente já são rodeados de estigmas; quando justapostos, percebe- 
se que a desinformação coopera para que estes estigmas se tornem ainda mais sólidos.

É importante ressaltar que as interpretações sobre a nova condição de vida sofrem interferência da dimensão social, visto que a significação da experiência vem acompanhada de uma bagagem de fatores culturais. A trajetória de vida de cada pessoa é importante no processo de identificar os aspectos psicológicos que sofrem impacto da deficiência, visto que cada indivíduo é singular.

Foram respondidos os objetivos de pesquisa, isto é, por meio deste estudo, foi possível investigar os aspectos psicológicos relacionados à nova condição de vida e compreender o impacto da deficiência física adquirida na vida de uma pessoa em relação a seus processos subjetivos. Além disso, este estudo verificou que as relações familiares, sociais e afetivas podem contribuir para a reestruturação da autoestima do indivíduo, fornecendo o apoio necessário; e validou que a autonomia durante a realização de atividades cotidianas pode interferir positivamente na autoestima, pois faz com que o indivíduo se sinta capaz.

Algumas limitações do estudo merecem ser citadas, como a não inclusão de outros idiomas e o estabelecimento dos anos de publicação. Os resultados identificados podem possibilitar reflexões para que novas pesquisas sejam realizadas nesta área, levando em consideração que poucos trabalhos recentes descrevem o impacto dos aspectos psicológicos na aquisição de uma deficiência.

\section{Referências}

Brasil. (1999). Decreto n. 3298 (20 de dezembro). Regulamenta a Lei n. 7.853, de 24 de outubro de 1989, dispõe sobre a Política Nacional para a Integração da Pessoa Portadora de Deficiência, consolida as normas de proteção, e dá outras providências. Brasília-DF. Recuperado de http://www.planalto.gov.br/ccivil_03/decreto/d3298.htm

Brasil. (2015). Lei n. 13.146 (6 de julho). Lei Brasileira de Inclusão da Pessoa com Deficiência. Estatuto da Pessoa com Deficiência. Brasília-DF. Recuperado de http://www.planalto.gov. br/ccivil_03/_ato2015-2018/2015/Lei/L13146.htm

Carvalho-Freitas, M. N., Silva, V. A., Tette, R. P. G., Veloso, H. S., Rocha, P. C. (2018). Retorno às atividades laborais entre amputados: Qualidade de vida no trabalho, depressão e ansiedade. Revista Psicologia Organizações e Trabalho, 18(4), 468-475. Recuperado de http://pepsic. bvsalud.org/scielo.php?pid=S1984-66572018000400003\&script=sci_abstract\&tIng=es

Instituto Brasileiro de Geografia e Estatística. (2013). Pesquisa Nacional de Saúde. Rio de Janeiro: IBGE. Recuperado de http://www.ibge.gov.br/home/estatistica/populacao/ pns/2013/

Lima, C. G.; Torres, I. P. F.; Rachid, N. R., Filho (2014). Aspectos psicológicos associados à sexualidade do lesado medular. Estação Científica. Recuperado de http://portal.estacio. br/docs\%5Crevista_estacao_cientifica/04.pdf

Lopes, E. M. C.; Leite, L. P. (2015). Deficiência adquirida no trabalho em policiais militares: Significados e sentidos. Psicologia \& Sociedade, 27(3), 668-677. Recuperado de http:// submission.scielo.br/index.php/psoc/article/view/136880

Maia, A. C. B. (2010). A importância das relações familiares para a sexualidade e a autoestima de pessoas com deficiência física. Portal dos Psicólogos, 1-10. Recuperado de http://www. psicologia.pt/artigos/textos/A0515.pdf 
Martins, J. A.; Barsaglini, R. A. (2010). Aspectos da identidade na experiência da deficiência física: Um olhar socioantropológico. Interface - Comunicação, Saúde, Educação, 15, p. 109-122. Acessado de https://www.scielosp.org/scielo. php?pid=S1414-32832011000100009\&script=sci_arttext\&tlng=pt

Mattos, C. D. (2015). O Processo de luto diante da deficiência física adquirida: Análise de um relato de caso. Psicologado, Edição 08/2015. Recuperado de https://psicologado.com.

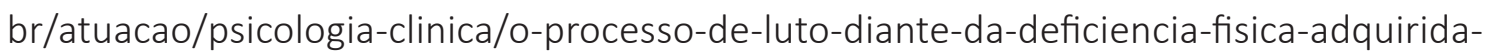
analise-de-um-relato-de-caso

Organização Mundial da Saúde [OMS]. (2011). Relatório Mundial sobre a Deficiência / World Report on Disability. The World Bank (Lexicus Serviços Linguísticos, trad.). São Paulo: SEDPcD. Recuperado de http://www.pessoacomdeficiencia.sp.gov.br/usr/share/ documents/RELATORIO_MUNDIAL_COMPLETO.pdf

Pimentel, S. C.; Pimentel, M. C. (2018). Ressignificando a deficiência: A necessidade de revisão conceitual para definição de políticas públicas. Revista Direitos Sociais e Políticas Públicas, 5(2), 1039-1054. Recuperado de http://dx.doi.org/10.25245/rdspp.v5i2.258

Resende, M. C.; Gouveia, V. V. (2011) Qualidade de vida em adultos com deficiência física. Psicologia: Reflexão e Crítica, 24(1), 99-106. Recuperado de http://www.scielo.br/pdf/ prc/v24n1/v24n1a12

Rodrigues, F.C.P.;Antunes, D. A. (2010). Considerações sobreo pacientecomlesãoraquimedular ou vítima de trauma: Um estudo qualitativo. Nursing, 13(150), 573-579. Recuperado de https://www.researchgate.net/profile/Francisco_Rodrigues9/publication/297730444_ CONSIDERACOES_SOBRE_O_PACIENTE_COM_LESAO_RAQUIMEDULAR_OU_VITIMA_ DE_TRAUMA_UM_ESTUDO_QUALITATIVO/links/56e1780a08aec09a8bc07b74/ CONSIDERACOES-SOBRE-O-PACIENTE-COM-LESAO-RAQUIMEDULAR-OU-VITIMA-DETRAUMA-UM-ESTUDO-QUALITATIVO.pdf

Santos, J. C., Carvalho-Freitas, M. N. (2018). Sentidos do trabalho para pessoas com deficiência adquirida. Psicologia \& Sociedade, 30, 1-1.. Recuperado de http://www.scielo. br/scielo.php?pid=S0102-71822018000100202\&script=sci_abstract\&tlng=es

Santos, W. S., Dias, J. C., Kian. G. C., Silva, P. Y. F., Rodrigues, L. B. (2015). Homens portadores de deficiência física adquirida: Estigmas e preconceitos vivenciados que interferem em sua sexualidade. Revista Interfaces: Saúde, Humanas e Tecnologia, 2(6), 1-5. Recuperado de http://interfaces.leaosampaio.edu.br/index.php/revista-interfaces/article/view/450

Silva, P. Y. F., Santos, W. S., Kian, G. C., Rodrigues, L. B. (2015). A expressão da sexualidade em homens portadores de deficiência física adquirida. Revista Interfaces: Saúde, Humanas e Tecnologia, 2(6), 1-4. Recuperado de http://interfaces.leaosampaio.edu.br/index.php/ revista-interfaces/article/view/452

Souza, M. T., Silva, M. D., Carvalho, R. (2010). Revisão integrativa: O que é e como fazer. Einstein, 8(1), pt 1, 102-106. Recuperado de http://www.scielo.br/pdf/eins/v8n1/ pt_1679-4508-eins-8-1-0102

Recebido em: 17/12/2019

Última revisão: 13/02/2020

Aceite final: $31 / 03 / 2020$ 


\section{Sobre os autores:}

Talitha Kshesek Pizarro de Oliveira: Graduada em Psicologia pela Pontifícia Universidade Católica do Paraná (PUCPR), Curitiba, PR. Psicóloga na Vivre Psicologia Clínica.E-mail: talithakshesek@gmail.com, Orcid: http://orcid.org/0000-0002-8369-1227

Camila Maia de Oliveira Borges Paraná: Mestre em Psicologia pela Universidade Federal do Paraná (UFPR). Professora do curso de Psicologia da Pontifícia Universidade Católica do Paraná (PUCPR), Curitiba. E-mail: camila.parana@pucpr.br, Orcid: http://orcid.org/0000-0002-3338-8836 